\title{
Development of Microsatellite Marker System to Determine the Genetic Diversity of Experimental Chicken, Duck, Goose, and Pigeon Populations
}

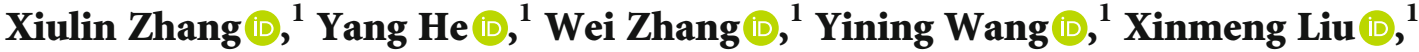 \\ Aique Cui $\mathbb{D}^{1},{ }^{1}$ Yidi Gong $\mathbb{D}^{1},{ }^{1}$ Jing Lu, ${ }^{1}$ Xin Liu, ${ }^{1}$ Xueyun Huo, ${ }^{1}$ Jianyi Lv, ${ }^{1}$ Meng Guo, ${ }^{1}$ \\ Xiaoyan Du, ${ }^{1}$ Lingxia Han, ${ }^{2}$ Hongyan Chen, ${ }^{2}$ Jilan Chen, ${ }^{3}$ Changlong Li $\mathbb{D}^{1}$ \\ and Zhenwen Chen $\left.{ }^{1}\right)^{1}$ \\ ${ }^{1}$ Capital Medical University, School of Basic Medical Sciences, Beijing 100069, China \\ ${ }^{2}$ Harbin Veterinary Research Institute of Chinese Academy of Agricultural Sciences, Harbin 150069, China \\ ${ }^{3}$ Institute of Animal Sciences, Chinese Academy of Agricultural Sciences, Beijing 100193, China
}

Correspondence should be addressed to Changlong Li; licl@ccmu.edu.cn and Zhenwen Chen; czwen@ccmu.edu.cn

Received 10 September 2020; Revised 9 December 2020; Accepted 5 January 2021; Published 15 January 2021

Academic Editor: Monica Fedele

Copyright (c) 2021 Xiulin Zhang et al. This is an open access article distributed under the Creative Commons Attribution License, which permits unrestricted use, distribution, and reproduction in any medium, provided the original work is properly cited.

Poultries including chickens, ducks, geese, and pigeons are widely used in the biological and medical research in many aspects. The genetic quality of experimental poultries directly affects the results of the research. In this study, following electrophoresis analysis and short tandem repeat (STR) scanning, we screened out the microsatellite loci for determining the genetic characteristics of Chinese experimental chickens, ducks, geese, and pigeons. The panels of loci selected in our research provide a good choice for genetic monitoring of the population genetic diversity of Chinese native experimental chickens, ducks, geese, and ducks.

\section{Introduction}

Laboratory animals are important experimental materials for science research. They play key roles in the investigation of pathogenesis, diagnosis of diseases, pharmaceutical research, and other fields [1]. The genetic quality of laboratory animals directly affects the accuracy, repeatability, and scientificity of medical biological research results. Genetic monitoring is one of the effective methods to evaluate population's genetic diversity. Through genetic monitoring, whether genetic mutations and genetic pollution occurred can be analyzed.

Poultry, including chicken, duck, goose, and pigeon, has become commonly used laboratory animals [2]. They are easy to reproduce and hatch in vitro. Among them, chickens are the most widely used poultry in life science research [3, 4]. Ducks, geese, and pigeons also play important roles in the research of epidemiology, immunology, virology, and pharmacotoxicology [5-9]. There are many genetic analysis and quality control methods applied to chickens $[10,11]$. However, at present, we find few reports about the genetic analysis systems and quality control methods of duck, goose, and pigeon populations, especially in the Chinese native groups.

Hence, in this study, we screened out the microsatellite loci with uniform distribution, stable amplification, and rich polymorphism in experimental chickens, ducks, geese, and pigeons with different genetic backgrounds [12]. We developed effective microsatellite marker systems to determine the genetic diversity of experimental chickens, ducks, geese, and pigeons, which will lay the foundation for the genetic quality control of them and promote the application of experimental poultry. 


\section{Materials and Methods}

2.1. Animal Sample. Three outbred groups and three haplotype groups of experimental chicken were used in this research: outbred group BWEL-SPF chickens ((SCXK (black) 2017-005)), 40 samples, 37 weeks old, 6 males and 34 females, which has been closed for 20 generations; outbred group BM chicken (from BWEL chicken lineage (SCXK (black) 2017-005)), 40 samples, 14 weeks old, 6 males and 34 females; outbred group Beijing oil chickens, 46 samples. MHC haplotype chickens were bred from the 13th generation of BWEL chicken, the haplotype was continuously selected based on the MHC core genes, and the half-sibling or sibling mating method was used to breed to the 8th generation [13]. We selected 5 G1 haplotype chickens, 53 weeks old, 1 male and 4 females; 5 G2 haplotype chickens, 93 weeks, 1 male and 4 females; and 5 G7 haplotype chickens, 82 weeks, 1 male and 4 females. The Beijing oil chickens came from the Institute of Animal Science (IAS), Chinese Academy of Agricultural Sciences (CAAS). Other samples were from Harbin Veterinary Research Institute (HVRI), CAAS. All the samples were blood.

Two outbred groups and four haplotype groups of experimental duck (bred from Jinding (JD) duck lineage (SCXK (black) 2017-006)) were selected: outbred group 1, 40 samples, 37 weeks old, 6 males and 34 females; outbred group JD duck, 40 samples, 37 weeks old, 6 males and 34 females; 10 A haplotype ducks, 53 weeks old, 1 male and 4 females; 10 B haplotype ducks, 53 weeks old, 1 male and 4 females; 10 C haplotype ducks, 53 weeks old, 1 male and 4 females; $10 \mathrm{D}$ haplotype ducks, 53 weeks old, 1 male and 4 females. All the samples are duck muscle tissue and were from HVRI, CAAS.

We collected two outbred groups of experimental geese: outbred group Guangdong Wuzong goose, 44 samples, 37 weeks old, 6 males and 34 females; outbred group Yangzhou goose, 44 samples, 37 weeks old, 6 males and 34 females. All the samples are goose liver tissue. Guangdong Wuzong geese were from Southern Medical University, and Yangzhou geese were from Yangzhou University.

Forty pigeons were randomly selected from two populations of white king pigeons and silver king pigeons, half male and half female, with no age limit. All the animals were from Liujinlong pigeon farms in Beijing. Their heart tissues were collected.

All breeding is carried out in accordance with Chinese agricultural standards NY/T 1901. What is more, all experiments followed the $3 \mathrm{R}$ principle.

2.2. Microsatellite Locus Selection. By searching PubMed and using SSR Hunter software to analyze animal gene information, we obtained microsatellite loci for further screening.

2.3. DNA Extraction. Phenol-chloroform extraction method was used to extract DNA from muscle, liver, and heart tissue. TIANamp Blood DNA Kits (Tiangen, Beijing, China) were used to extract DNA from chicken blood samples. All DNA concentrations were diluted to $50 \mathrm{ng} / \mu \mathrm{L}$, stored in $-20^{\circ} \mathrm{C}$.
2.4. PCR Procedure and Agarose Gel Electrophoresis. The PCR was performed in a $20 \mu \mathrm{L}$ reaction volume containing $10 \mu \mathrm{L}$ Dream Taq Green PCR Master Mix (Thermo Fisher Scientific, Massachusetts, MA), $2 \mu \mathrm{L}$ pure water $\left(\mathrm{ddH}_{2} \mathrm{O}\right), 10 \mathrm{pmol}$ each primer, and $50 \mathrm{ng}$ of the extracted DNA template. The PCR protocol was as follows: $94^{\circ} \mathrm{C}$ for $5 \mathrm{~min}$, followed by 35 cycles of $94^{\circ} \mathrm{C}$ for $30 \mathrm{~s}$, suitable temperature for $30 \mathrm{~s}, 72^{\circ} \mathrm{C}$ for $30 \mathrm{~s}$, and a final extension at $72^{\circ} \mathrm{C}$ for $5 \mathrm{~min}$. Amplified products were stored at $-20^{\circ} \mathrm{C}$ for further analysis.

Amplified products were electrophoresed on a $2 \%$ agarose gel at $130 \mathrm{~V}, 90 \mathrm{~min}$.

2.5. STR Scanning. We performed STR scanning on PCR amplification products of candidate loci. The forward primers of candidate microsatellite loci were fluorescent labelled with FAM, HEX, and TAMRA. The sample genome was amplified with fluorescent primers, and the amplified products were scanned by STR through 3730xl DNA Analyzer (Applied Biosystems, Thermo Fisher Scientific, Massachusetts, USA). All the STR scanning was performed by Beijing Tianyi Huiyuan Biotechnology Co., Ltd.

2.6. Data Analysis. GeneMarker V2.2.0 software was used to analyze the length of amplified fragments from different populations at each microsatellite locus. Popgene 3.2 software was used to analyze the observed number of alleles, effective number of alleles, Shannon's information index, and effective heterozygosity of microsatellite loci. The polymorphic information content of multiple sites was calculated using PIC calculation software (PIC_CALC.0.6).

\section{Results}

\subsection{Microsatellite Locus Selection}

3.1.1. Preliminary Screening of Microsatellite Loci by PCR. Firstly, we obtained the microsatellite locus information of experimental chickens, ducks, geese, and pigeons by searching previous reports on PubMed and using the SSR Hunter software to analyze the genetic information of different populations $[14,15]$. We collected 72, 59, 57, and 61 microsatellite loci of experimental chicken, duck, goose, and pigeon, respectively.

In order to clarify the amplification conditions of the microsatellite loci and exclude the loci with poor specificity, we performed temperature gradient PCR and agarose gel electrophoresis of microsatellite loci. Then, we performed PCR amplification on the most suitable conditions and subjected the PCR products to agarose gel electrophoresis to screen out loci with suitable length, good polymorphism in outbred groups, good monomorphism in haplotypes, and high specificity. Taking the chicken GGNCAMZO locus and duck AY264 locus as example, the results are shown in Figure 1. GGNCAMZO locus is monomorphic in the haplotype chicken population, and AY264 locus is polymorphic in the outbred duck group.

In summary, we selected 37 and 32 microsatellite loci with good polymorphism in the outbred groups and haplotypes of chicken, respectively $[12,16,17]$. In addition, 15 and 23 loci 


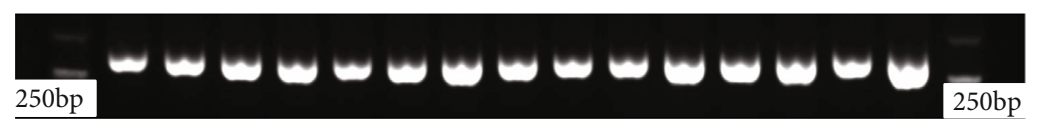

(a)

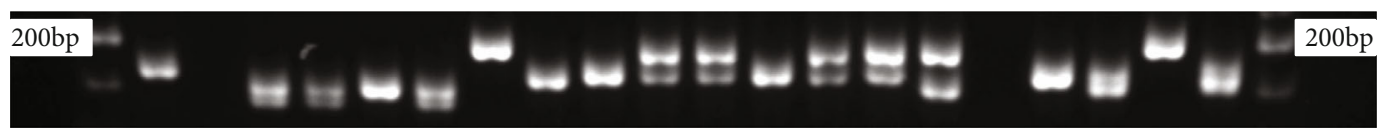

(b)

FIGURE 1: Results of agarose gel electrophoresis of microsatellite DNA locus GGNCAMZO in experimental chickens and locus AY264 in experimental ducks. (a) GGNCAMZO in haplotype chicken line G1. (b) AY264 in the outbred group of experimental ducks.

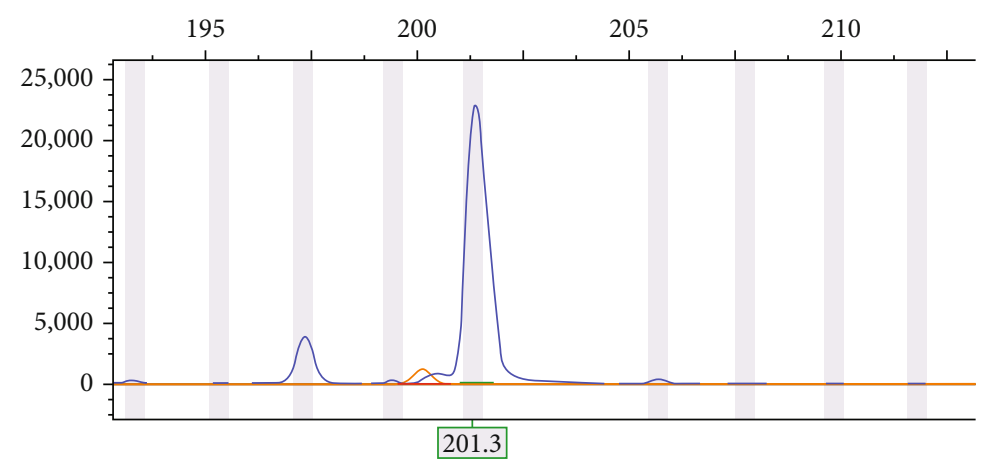

(a)

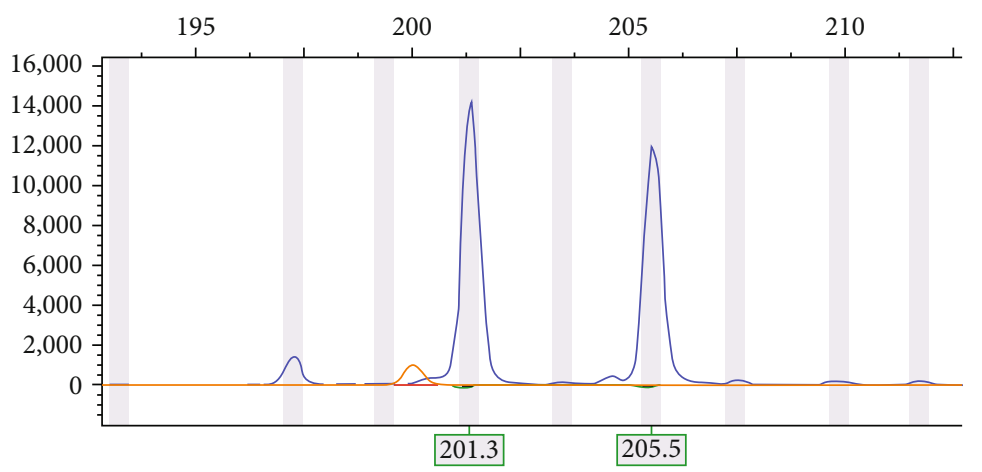

(b)

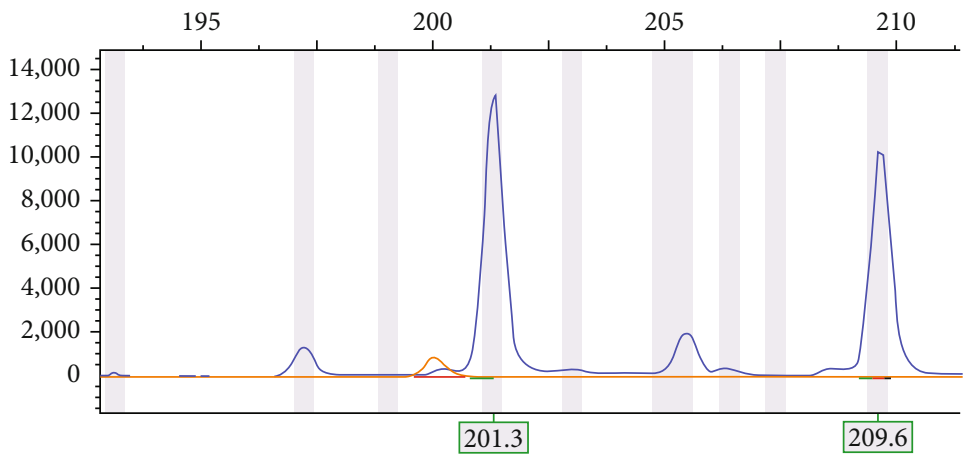

(c)

Figure 2: Results of UU-Cli $\mu$ T47 scan of the experimental pigeons. (a) The STR graph corresponding to the sample of haplotype under primer UU-Cli $\mu$ T47 shows homozygote with a wave peak of $201 \mathrm{bp}$. (b) The STR diagram corresponding to the sample of outbred groups under primer UU-Cli $\mu$ T47 shows heterozygote with two wave peaks of $201 \mathrm{bp}$ and $205 \mathrm{bp}$, respectively. (c) The STR diagram corresponding to the sample of outbred groups under primer UU-Cli $\mu$ T47 shows heterozygote with two wave peaks of $201 \mathrm{bp}$ and $209 \mathrm{bp}$, respectively. 
TABLE 1: Number of alleles, optimal amplification conditions, and fragment length of 29 alleles for the laboratory chickens.

\begin{tabular}{|c|c|c|c|c|}
\hline Loci & Primer sequence $\left(5^{\prime}-3^{\prime}\right)$ & Temperature $\left({ }^{\circ} \mathrm{C}\right)$ & Allele range & Applicable groups \\
\hline \multirow{2}{*}{ MCW0029 } & GTGGACACCCATTTGTACCCTATG & \multirow{2}{*}{63.8} & \multirow{2}{*}{$139-188$} & \multirow{2}{*}{ Outbred group } \\
\hline & CATGCAATTCAGGACCGTGCA & & & \\
\hline \multirow{2}{*}{ ADL0293 } & GTAATCTAGAAACCCCATCT & \multirow{2}{*}{53.9} & \multirow{2}{*}{$106-120$} & \multirow{2}{*}{ Outbred group } \\
\hline & ACATACCGCAGTCTTTGTTC & & & \\
\hline \multirow{2}{*}{ ADL0317 } & AGTTGGTTTCAGCCATCCAT & \multirow{2}{*}{58.5} & \multirow{2}{*}{$177-219$} & \multirow{2}{*}{ Outbred group } \\
\hline & CCCAGAGCACACTGTCACTG & & & \\
\hline \multirow{2}{*}{ GCT0016 } & TCCAAGGTTCTCCAGTTC & \multirow{2}{*}{52.2} & \multirow{2}{*}{$111-148$} & \multirow{2}{*}{ Outbred group } \\
\hline & GGCATAAGGATAGCAACAG & & & \\
\hline \multirow{2}{*}{ ADL0304 } & GGGGAGGAACTCTGGAAATG & \multirow{2}{*}{53.9} & \multirow{2}{*}{$138-161$} & \multirow{2}{*}{ Outbred group } \\
\hline & CCTCATGCTTCGTGCTTTTT & & & \\
\hline \multirow{2}{*}{ LEI0074 } & GACCTGGTCCTGACATGGGTG & \multirow{2}{*}{58.5} & $221-243$ & Outbred oroun \\
\hline & GTTTGCTGATTAGCCATCGCG & & $221-245$ & anturea group \\
\hline ADL 328 & CACCCATAGCTGTGACTTTG & 539 & $107-120$ & Outbred oroun \\
\hline 月DLOC & AAAACCGGAATGTGTAACTG & ( & $107-120$ & 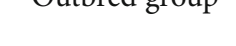 \\
\hline GGANTECl & GCGGGGCCGTTATCAGAGCA & 650 & $139-194$ & Outbred oroun \\
\hline Goniv Let & AGTGCAGGGCGCTCCTGGT & 03.0 & (10)-194 & 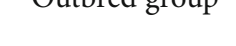 \\
\hline LEJ094 & CAGGATGGCTGTTATGCTTCCA & 560 & $176-211$ & Outbred groun \\
\hline LEIVP4 & CACAGTGCAGAGTGGTGCGA & 30.0 & $1 / 0-211$ & 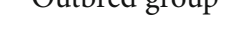 \\
\hline MCW0330 & TGGACCTCATCAGTCTGACAG & 585 & $217-287$ & Outbred aroun \\
\hline DIC & AATGTTCTCATAGAGTTCCTGC & $30 . J$ & $211-20 \%$ & antorea group \\
\hline LFJ0141 & CGCATTTGATGCATAACACATG & 522 & $221-245$ & Outbred oroun \\
\hline LEIVIT1 & AAGGCAAACTCAGCTGGAACG & 32.2 & $221-24 J$ & Gatorea group \\
\hline MCW0087 & ATTTCTGCAGCCAACTTGGAG & 585 & $268-289$ & Outbred group \\
\hline 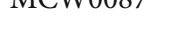 & CTCAGGCAGTTCTCAAGAACA & 30.5 & $200-209$ & Gatorea gioup \\
\hline MCW0347 & GCTTCCAGATGAGCTCCATGG & 52.0 & $121-149$ & Outbred group \\
\hline (1) & CACAGCGCTGCAGCAACTG & 52.0 & $121-149$ & Gutorea group \\
\hline ADL176 & TTGTGGATTCTGGTGGTAGC & 58.5 & $183-200$ & Outbred oroun \\
\hline ADL1/O & TTCTCCCGTAACACTCGTCA & 30.3 & $183-200$ & Gutorea group \\
\hline ADL0201 & GCTGAGGATTCAGATAAGAC & 58.5 & $111-151$ & Outbred oroun \\
\hline ADLOZOI & AATGGCYGACGTTTCACAGC & 58.3 & $111-151$ & Gutored group \\
\hline GGNCAM7O & GTCACTAGGTTAGCAGCATG & 560 & 234 & Outbred group \\
\hline GGNCAIVILU & GCTGGATACAGACCTCGATT & 50.0 & 234 & Haplotype \\
\hline CGAVIR & AGAGATGGTGCACGCAACCT & 607 & 8680 & Outbred group \\
\hline GGAVIK & CGAGCACTTTCTGGCAGAGA & 00.1 & $80-89$ & Haplotype \\
\hline MCW00063 & GGCTCCAAAAGCTTGTTCTTAGCT & 530 & $116-1$ & Outbred group \\
\hline MLW0063 & GAAAACCAGTAAAGCTTCTTAC & 53.9 & $116-146$ & Haplotype \\
\hline ADI 185 & CATGGCAGCTGACTCCAGAT & 585 & $116-14$ & Outbred group \\
\hline ADLI85 & AGCGTTACCTGTTCGTTTGC & 58.5 & $110-142$ & Haplotype \\
\hline GGMYC & CGAGGCGCTCTGCGAGTTTA & 624 & $139-15$ & Outbred group \\
\hline GGMYY & TGGGGACCTCTGGCTCTGAC & 02.4 & $139-151$ & Haplotype \\
\hline IFI0094 & GATCTCACCAGTATGAGCTGC & 539 & $250-28$ & Outbred group \\
\hline LL10074 & TCTCACACTGTAACACAGTGC & JJ. & $200-200$ & Haplotype \\
\hline GGVITC & AGCCATCATTCAGGGCATCT & 585 & 86 & Outbred group \\
\hline Guvile & GATGTCCTGAGTGATGCTCA & $30 . J$ & 00 & Haplotype \\
\hline ADI 0202 & CCAAATCAGGCAAAACTTCT & 585 & $110-13$ & Outbred group \\
\hline ADLOLY & AAATGGCCTAAGGATGAGGA & 58.5 & $110-136$ & Haplotype \\
\hline GGVITIIG & GGCAGGTTTCTAATGCCTGA & 56.0 & $186-189$ & Outbred group \\
\hline & CCCATCGTTTCAACTGTATG & & $100-109$ & Haplotype \\
\hline
\end{tabular}


TABle 1: Continued.

\begin{tabular}{|c|c|c|c|c|}
\hline Loci & Primer sequence $\left(5^{\prime}-3^{\prime}\right)$ & Temperature $\left({ }^{\circ} \mathrm{C}\right)$ & Allele range & Applicable groups \\
\hline \multirow{2}{*}{ ADL166 } & TGCCAGCCCGTAATCATAGG & \multirow{2}{*}{58.5} & \multirow{2}{*}{$131-154$} & Outbred group \\
\hline & AAGCACCACGACCCAATCTA & & & Haplotype \\
\hline \multirow{2}{*}{ MCW0014 } & AAAATATTGGCTCTAGGAACTGTC & \multirow{2}{*}{58.5} & \multirow{2}{*}{$172-195$} & Outbred group \\
\hline & ACCGGAAATGAAGGTAAGACTAGC & & & Haplotype \\
\hline \multirow{2}{*}{ GGCYMA } & AGCGAGGCGCTCTGCGAGTT & \multirow{2}{*}{64.6} & \multirow{2}{*}{$140-153$} & Outbred group \\
\hline & GGGCACCTCTGGCTCTGACC & & & Haplotype \\
\hline \multirow{2}{*}{ MCW0402 } & ACTGTGCCTAGGACTAGCTG & \multirow{2}{*}{56.0} & \multirow{2}{*}{$141-229$} & Outbred group \\
\hline & CCTAAGTCTGGGCTCTTCTG & & & Haplotype \\
\hline \multirow{2}{*}{ STMSGGHU2-1A } & CTTAATATGTGTGAGGTGGC & \multirow{2}{*}{53.9} & \multirow{2}{*}{$235-238$} & \multirow{2}{*}{ Haplotype } \\
\hline & GTTCTCACAATTGCATTAGC & & & \\
\hline
\end{tabular}

were screened in the outbred groups and haplotypes of duck, respectively $[14,18,19]$. In the outbred groups of goose and pigeon, 14 and 20 microsatellite loci were chosen [18, 2023]. Loci in these panels would be candidate for the final microsatellite marker evaluation systems.

3.1.2. STR Scanning Analysis. In order to further complete the microsatellite marker system, we performed STR scanning on the candidate microsatellite DNA loci matched microsatellite criteria and analyzed the length of the amplified product at the peak with GeneMarker software (V1.75). Taking the UU-Cli $\mu$ T47 locus as an example, it showed polymorphism in the outbred group of pigeon (Figure 2).

We finally determined that in experimental chickens, 28 loci were selected for genetic monitoring in the outbred groups and 14 loci for haplotypes. All microsatellite DNA loci are shown in Table 1 . There are 13 common loci.

In experimental duck populations, we chose 25 loci and 15 loci for genetic monitoring in the outbred duck groups and haplotype groups. There are 12 common loci. Microsatellite loci are shown in Table 2.

14 microsatellite loci with good polymorphism were considered as microsatellite markers in the outbred group of goose. Table 3 demonstrates the number of alleles, optimal amplification conditions, and fragment length of 14 alleles for the outbred experiment geese.

In the outbred group of pigeon, we finally screened out 16 microsatellite loci with good polymorphism, several alleles, and typical stutter peaks. All microsatellite locus information is shown in Table 4.

3.1.3. Analysis of Population Microsatellite Loci. We inputted the results of STR scanning into Popgene 3.2 to analyze experimental chicken in the outbred groups and the haplotypes at 29 loci. In the outbred groups, 28 microsatellite loci show a high degree of polymorphism, and the average number of observed alleles is 4.571 . The average number of effective alleles is 3.270, and the average Shannon's information index is 1.198 (Table 5). Furthermore, the average effective heterozygosity is 0.492 . The average polymorphism information content (PIC) is 0.610 . All these data indicate a good genetic diversity of screening loci in the outbred groups and large heterozygosity difference among the laboratory experimental chicken populations.

In the other 3 haplotype populations, 14 microsatellite loci showed monomorphism in each population but showed different lengths in different haplotype populations. The average number of observed alleles is 1.571 . The average number of effective alleles, the average Shannon's information index, and the average effective heterozygosity are $1.433,0.316$, and 0.207 , respectively (Table 6 ). The specific data of each haplotype population is shown in Supplementary Tables 1-3.

In the outbred group of duck, 25 microsatellite loci show polymorphism. The average number of observed alleles is 7.520 , and the average number of effective alleles in the population is 4.162. The average Shannon's information index is 1.574 , and the average effective heterozygosity is 0.683 . The average PIC is 0.698 . These data showed that in the outbred groups, the genetic diversity of microsatellite DNA loci is better, and the genetic diversity of each locus is quite different. The specific results are shown in Table 7.

In 4 haplotype populations, 15 microsatellite loci show monomorphism in each population. The average number of observed alleles is 4.133 , the average number of effective alleles is 2.863 , and the average Shannon's information index is 1.153 , indicating that the genetic diversity of the loci in these haplotype populations is poor; the average effective heterozygosity is 0.500 , indicating that the heterozygosity difference is small and the genetic information of the selected loci is relatively single. See Table 8 for more detailed information, and the specific data in each haplotype population is shown in Supplementary Tables 4-7.

In the outbred colony of experimental goose, 14 loci were selected. The average number of observed alleles, the average number of effective alleles, the average Shannon's information index, the average effective heterozygosity, and the PIC are $4.714,3.038,1.195,0.528$, and 0.582 , respectively. The microsatellite loci have large interindividual differences within the population, and the population has high gene stability (Table 9).

The selected microsatellite loci all show good polymorphism in the experimental outbred pigeon populations. A total of 16 loci were selected. The average number of observed alleles is 7.875 . The average effective allele number 
TABLE 2: Number of alleles, optimal amplification conditions, and fragment length of 28 alleles for the laboratory ducks.

\begin{tabular}{|c|c|c|c|c|}
\hline Loci & Primer sequence $\left(5^{\prime}-3^{\prime}\right)$ & Temperature $\left({ }^{\circ} \mathrm{C}\right)$ & Allele range & Applicable groups \\
\hline \multirow{2}{*}{ CAUD007 } & ACTTCTCTTGTAGGCATGTCA & \multirow{2}{*}{60.8} & \multirow{2}{*}{$100-190$} & \multirow{2}{*}{ Outbred group } \\
\hline & CACCTGTTGCTCCTGCTGT & & & \\
\hline \multirow{2}{*}{ CAUD004 } & TCCACTTGGTAGACCTTGAG & \multirow{2}{*}{60.8} & \multirow{2}{*}{ 234-385 } & \multirow{2}{*}{ Outbred group } \\
\hline & TGGGATTCAGTGAGAAGCCT & & & \\
\hline \multirow{2}{*}{ CAUD023 } & CACATTAACTACATTTCGGTCT & \multirow{2}{*}{51.4} & \multirow{2}{*}{$163-234$} & \multirow{2}{*}{ Outbred group } \\
\hline & CAGCCAAAGAGTTCAACAGG & & & \\
\hline \multirow{2}{*}{ CAUD027 } & AGAAGGCAGGCAAATCAGAG & \multirow{2}{*}{66.0} & \multirow{2}{*}{$70-180$} & \multirow{2}{*}{ Outbred group } \\
\hline & TCCACTCATAAAAACACCCACA & & & \\
\hline \multirow{2}{*}{ CAUD001 } & ACAGCTTCAGCAGACTTAGA & \multirow{2}{*}{55.5} & \multirow{2}{*}{$150-247$} & \multirow{2}{*}{ Outbred group } \\
\hline & GCAGAAAGTGTATTAAGGAAG & & & \\
\hline \multirow{2}{*}{ CAUD031 } & AGCATCTGGACTTTTTCTGGA & \multirow{2}{*}{51.4} & $107-187$ & Outbred group \\
\hline & CACCCCAGGCTCTGAGATAA & & & \\
\hline CAUD032 & GAAACCAACTGAAAACGGGC & 581 & $96-206$ & Outbred oroun \\
\hline (2) & CCTCCTGCGTCCCAATAAG & 30.1 & $30=200$ & 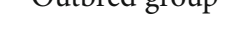 \\
\hline AY 314 & CTCATTCCAATTCСТCTGTA & 503 & $112-329$ & Outbred oroun \\
\hline К1 & CAGCATTATTATTTCAGAAGG & 30.0 & $112-525$ & 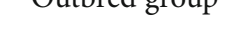 \\
\hline CMO211 & GGATGTTGCCCCACATATTT & 550 & 205-205 & Outbred oroun \\
\hline Civituati & TTGCCTTGTTTATGAGCCATT & 50.0 & $112-203$ & unted group \\
\hline АРН 09 & GGATGTTGCCCCACATATTT & 580 & $134-190$ & Outbred aroun \\
\hline RFIIOS & TTGCCTTGTTTATGAGCCATTA & 30.0 & $154-190$ & a durea group \\
\hline APH11 & GGACCTCAGGAAAATCAGTGTA & & & \\
\hline MFI111 & GCAGGCAGAGCAGGAAATA & 58.5 & $183-185$ & Uutored group \\
\hline APL2 & GATTCAACCTTAGCTATCAGTCTCC & 58.5 & $115-125$ & Outbred group \\
\hline MILL & CGCTCTTGGCAAATGTCC & 30.3 & $110-125$ & Gutviea givap \\
\hline CAUD011 & TGCTATCCACCCAATAAGTG & 503 & $145-223$ & Outbred group \\
\hline CAUDOII & CAAAGTTAGCTGGTATCTGC & 50.3 & $145-225$ & Vutorea group \\
\hline CAUDOO6 & ATGGTTCTCTGTAGGCAATC & 635 & 182,290 & Outbred group \\
\hline CAUDOUO & TTCTGCTTGGGCTCTTGGA & 03.3 & $183-290$ & Haplotype \\
\hline CAUD018 & TTAGACAAATGAGGAAATAGTA & 503 & 100.180 & Outbred group \\
\hline CAUDOIO & GTCCAAACTAAATGCAGGC & 50.3 & $100-100$ & Haplotype \\
\hline CAUD010 & GGATGTGTTTTTCATTATTGAT & 503 & 128,0 & Outbred group \\
\hline CAUDOIO & AGAGGCATAAATACTCAGTG & 30.3 & $130-200$ & Haplotype \\
\hline CAUDO12 & ATTGCCTTTCAGTGGAGTTTC & 635 & $182-286$ & Outbred group \\
\hline CAUDOIL & CGGCTCTAAACACATGAATG & 03.5 & $182-280$ & Haplotype \\
\hline CAUDO14 & CACAACTGACGGCACAAAGT & 581 & $136-200$ & Outbred group \\
\hline CAUDO14 & CTGAGTTTTTCCCGCCTCTA & 58.1 & $136-200$ & Haplotype \\
\hline CAUD0 34 & TACTGCATATCACTAGAGGA & 555 & $160-296$ & Outbred group \\
\hline CAUD034 & TAGGCATACTCGGGTTTAG & 55.5 & $160-296$ & Haplotype \\
\hline CAUD035 & GTGCCTAACCCTGATGGATG & 635 & 174-282 & Outbred group \\
\hline CAUDOS5 & CTTATCAGATGGGGCTCGGA & 03.5 & $1 / 4-282$ & Haplotype \\
\hline API 579 & ATTAGAGCAGGAGTTAGGAGAC & 550 & & Outbred group \\
\hline APL5/9 & GCAAGAAGTGGCTTTTTTC & 55.0 & $116-227$ & Haplotype \\
\hline AY 258 & ATGTCTGAGTCCTCGGAGC & 581 & $89-16$ & Outbred group \\
\hline A12J0 & ACAATAGATTCCAGATGCTGAA & 50.1 & $89-162$ & Haplotype \\
\hline $\mathrm{CMO} 212$ & CTCCACTAGAACACAGACATT & 58.0 & & Outbred group \\
\hline & CATCTTTGGCATTTTGAAG & 58.0 & $186-272$ & Haplotype \\
\hline CAUD028 & TACACCCAAGTTTATTCTGAG & 55.5 & $152-226$ & Outbred group \\
\hline & ACTCTCCAGGGCACTAGG & & & Haplotype \\
\hline
\end{tabular}


TABLE 2: Continued.

\begin{tabular}{lcccc}
\hline Loci & Primer sequence $\left(5^{\prime}-3^{\prime}\right)$ & Temperature $\left({ }^{\circ} \mathrm{C}\right)$ & Allele range & Applicable groups \\
\hline CAUD026 & $\begin{array}{c}\text { ACGTCACATCACCCCACAG } \\
\text { CTTTGCCTCTGGTGAGGTTC }\end{array}$ & 60.8 & $134-196$ & $\begin{array}{c}\text { Outbred group } \\
\text { APH18 }\end{array}$ \\
$\begin{array}{l}\text { TTCTGGCCTGATAGGTATGAG } \\
\text { GAATTGGGTGGTCATACTGT }\end{array}$ & 58.0 & $178-325$ & Haplotype \\
CAUD002 & $\begin{array}{l}\text { CTTCGGTGCCTGTCTTAGC } \\
\text { AGCTGCCTGGAGAAGGTCT }\end{array}$ & 60.8 & $200-231$ & Haplotype \\
CAUD005 & $\begin{array}{l}\text { CTGGGTTTGGTGAGCATAA } \\
\text { TACTGGCTGCTTCATTGCTG }\end{array}$ & 60.8 & $184-290$ & Haplotype \\
\hline
\end{tabular}

TABLe 3: Number of alleles, optimal amplification conditions, and fragment length of 14 alleles for the outbred colony laboratory geese.

\begin{tabular}{|c|c|c|c|}
\hline Loci & Primer sequence $\left(5^{\prime}-3^{\prime}\right)$ & Temperature $\left({ }^{\circ} \mathrm{C}\right)$ & Allele range \\
\hline \multirow{2}{*}{ G-Ans17 } & ACAAATAACTGGTTCTAAGCAC & \multirow{2}{*}{51.0} & \multirow{2}{*}{$111-123$} \\
\hline & AGAGGACTTCTATTCATAAATA & & \\
\hline \multirow{2}{*}{ G-TTUCG1 } & CCCTGCTGGTATACCTGA & \multirow{2}{*}{53.0} & \multirow{2}{*}{ 113-115 } \\
\hline & GTGTCTACACAACAGC & & \\
\hline \multirow{2}{*}{ G-APH13 } & CAACGAGTGACAATGATAAAA & \multirow{2}{*}{53.0} & \multirow{2}{*}{$163-165$} \\
\hline & CAATGATCTCACTCCCAATAG & & \\
\hline \multirow{2}{*}{ G-Ans02 } & TTCTGTGCAGGGGCGAGTT & \multirow{2}{*}{58.0} & \multirow{2}{*}{$202-230$} \\
\hline & AGGGAACCGATCACGACATG & & \\
\hline \multirow{2}{*}{ G-Ans07 } & GACTGAGGAACTACAATTGACT & \multirow{2}{*}{62.0} & \multirow{2}{*}{$236-246$} \\
\hline & ACAAAGACTACTACTGCCAAG & & \\
\hline \multirow{2}{*}{ G-Ans 18} & GTGTTCTCTGTTTATGATATTAC & \multirow{2}{*}{56.0} & \multirow{2}{*}{$229-237$} \\
\hline & AACAGAATTTGCTTGAAACTGC & & \\
\hline \multirow{2}{*}{ G-Ans25 } & САCTTATTAATGGCACTTGAAA & \multirow{2}{*}{62.0} & \multirow{2}{*}{$261-277$} \\
\hline & GTTCTCTTGTCACAACTGGA & & \\
\hline \multirow{2}{*}{ G-Hhi $\mu 1 b$} & ATCAAAGGCACAATGTGAAAT & \multirow{2}{*}{60.0} & \multirow{2}{*}{$212-216$} \\
\hline & AGTAAGGGGGCTTCCACC & & \\
\hline \multirow{2}{*}{ G-CKW47 } & AACTTCTGCACСТAAAAACTGTCA & \multirow{2}{*}{56.0} & \multirow{2}{*}{ 213-215 } \\
\hline & TGCTGAGGTAACAGGAATTAAAA & & \\
\hline \multirow{2}{*}{ G-Bса $\mu 5$} & AGTGTTTCTTTCATCTCCACAAGC & \multirow{2}{*}{56.0} & \multirow{2}{*}{$197-201$} \\
\hline & AGACCACAATCGGACCACATATTC & & \\
\hline \multirow{2}{*}{ G-Bса $\mu 7$} & TAGTTTCTATTTGCACCCAATGGAG & \multirow{2}{*}{60.0} & \multirow{2}{*}{$171-175$} \\
\hline & CGGTCCTGTCCTTGTGCTGTAA & & \\
\hline G-Bса $\mu 8$ & CCCAAGACTCACAAAACCAGAAAT & 580 & $155-159$ \\
\hline U-Dса & ATGAAAGAAGAGTTAAACGTGTGCAA & 30.0 & $153-159$ \\
\hline G-CAUD006 & ATGGTTCTCTGTAGGCAATC & 560 & $170-210$ \\
\hline & TTCTGCTTGGGCTCTTGGA & & \\
\hline G-APH20 & ACCAGCCTAGCAAGCACTGT & 53.0 & $140-150$ \\
\hline U-ATाILO & GAGGCTTTAGGAGAGATTGAAAAA & & \\
\hline
\end{tabular}

is 4.554; the average Shannon's information index and the average effective heterozygosity are 1.559 and 0.649 . The average PIC is 0.674 (Table 10).

3.1.4. Population Genetic Structure Analysis. Among the three outbred chicken groups, the mean number of observed alleles, the mean number of effective alleles, the mean Shan- non's information index, and the mean effective heterozygosity are shown in Table 11. All these data are the highest in the Beijing oil chicken, indicating the best gene diversity.

In the haplotype chicken populations, the highest mean observed number of alleles is observed in G7groups. Haplotype G7 has the highest mean effective allele number and the highest mean Shannon's information index. The mean 
TABLE 4: Number of alleles, optimal amplification conditions, and fragment length of 16 alleles for the outbred colony laboratory pigeons.

\begin{tabular}{|c|c|c|c|}
\hline Loci & Primer sequence $\left(5^{\prime}-3^{\prime}\right)$ & Temperature $\left({ }^{\circ} \mathrm{C}\right)$ & Allele range \\
\hline \multirow{2}{*}{ UU-Cli02 } & TGGGCAAGGTACACTTTTAGGT & \multirow{2}{*}{61.0} & \multirow{2}{*}{$158-170$} \\
\hline & CTTTATGCTCCCCCTTGAGAT & & \\
\hline \multirow{2}{*}{ UU-Cli06 } & TTTGAAAAACATGGATTGTGC & \multirow{2}{*}{56.0} & \multirow{2}{*}{$140-145$} \\
\hline & AATTTGCAGAGGGTGAGTGG & & \\
\hline \multirow{2}{*}{ PG5 } & GTTCTTGGTGTTGCATGGATGC & \multirow{2}{*}{59.0} & \multirow{2}{*}{$262-266$} \\
\hline & AGTTACGAAATGATTGCCAGAAG & & \\
\hline \multirow{2}{*}{ C26L9(1265223) } & CAAAGCTGCTGACGTGAATCAA & \multirow{2}{*}{59.0} & \multirow{2}{*}{$467-472$} \\
\hline & AGAGACGCTCCATGCAAAAG & & \\
\hline \multirow{2}{*}{ UU-Cli14 } & CAGAACGTTTTGTTCTGTTTGG & \multirow{2}{*}{58.0} & \multirow{2}{*}{$265-292$} \\
\hline & TCTTGCTGCAGTCTTCATCC & & \\
\hline \multirow{2}{*}{ C12L1(532572) } & GTTGTTTGGCTGAGTGGACG & \multirow{2}{*}{62.0} & \multirow{2}{*}{$126-136$} \\
\hline & TCAACCAGGGGAATTGGCAG & & \\
\hline \multirow{2}{*}{ C12L4(906353) } & GCTGCTGTCTTCTTCATTGGG & \multirow{2}{*}{60.0} & \multirow{2}{*}{$210-250$} \\
\hline & TTAAAACCTCCCGTCTCCCTG & & \\
\hline \multirow{2}{*}{ Cli $\mu \mathrm{D} 11$} & CCAATCCCAAAGAGGATTAT & \multirow{2}{*}{58.0} & \multirow{2}{*}{$78-98$} \\
\hline & ACTGTCCTATGGCTGAAGTG & & \\
\hline \multirow{2}{*}{ C26L10(1404758) } & GCTGTCAGGTATCAGCCACAA & \multirow{2}{*}{59.0} & \multirow{2}{*}{$211-226$} \\
\hline & TCAGACCCACGAAAGCTGTAA & & \\
\hline \multirow{2}{*}{ C26L4(568923) } & CAACCCCATGTGGGTGAGAC & \multirow{2}{*}{63.0} & \multirow{2}{*}{$357-432$} \\
\hline & CACCACCACGTGGGACATC & & \\
\hline \multirow{2}{*}{ PG4 } & CCCATCTCCTGCCTGATGC & 640 & $136-170$ \\
\hline & CACAGCAGGATGCTGCCTGC & 04.0 & (50-1/ \\
\hline UUI_Cli12 & CGCCAGACTGTATTGTGAGC & 610 & $231-265$ \\
\hline U-Ciniz & AGCATGGCTGTTCTTTGAGG & & \\
\hline CliuT47 & ATGTGTGTTTGTGCATGAAG & 560 & $183-214$ \\
\hline$-11 \mu 14$ / & ATGAAAGCCTGTTAGTGGAA & 50.0 & $103-214$ \\
\hline CliuD32 & GAGCCATTTCAGTGAGTGACA & 600 & $136-158$ \\
\hline Сाн & GTTTGCAGGAGCGTGTAGAGAAGT & 00.0 & $150-158$ \\
\hline UU-Cli07 & GCTGCCTGTTACTACCTGAGC & 610 & $277-310$ \\
\hline 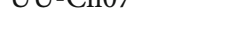 & CTGGCCATGAAATGAACTCC & 01.0 & $213=-510$ \\
\hline C26L 1) 20390$)$ & AGGAGCCTACACTGGGTTTTC & 600 & $250-268$ \\
\hline $\operatorname{CoOL1}(20390)$ & TGTAGCTCTGCAATCAGCCT & 00.0 & $250-208$ \\
\hline
\end{tabular}

effective heterozygosity of haplotype G7 is 0.364 . The genetic heterozygosity of the 3 populations is very low, and the consistency is good (Table 12).

In the two outbred groups of duck, the mean number of observed alleles, the mean effective number of alleles, the mean Shannon's index, and the mean effective heterozygosity of outbred group 1 are higher than those of outbred group JD, indicating that outbred group 1 had better diversity. The results are shown in Table 13. Among the 4 haplotype populations, the highest mean number of alleles is observed in haplotype A. Haplotype A has the highest mean Shannon's information index. The highest mean effective heterozygosity in the duck groups is 0.489 in haplotype A (Table 14). The genetic heterozygosity of 4 populations is in good agreement.

In the two outbred groups of goose, the mean number of observed alleles, the mean effective number of alleles, and the mean Shannon's index of Guangdong Wuzong goose are higher than those of Yangzhou goose, indicating that Guangdong Wuzong goose has a better diversity (Table 15).

The analysis of the two main experimental pigeon populations used for scientific research shows that the mean effective heterozygosity of two populations is 0.647 and 0.651 , respectively. The mean number of observed alleles, the mean effective number of alleles, and the mean Shannon's index are higher in white king pigeons than in silver king pigeons. The comparison of the data is shown in Table 16.

\section{Discussion}

Poultries are widely used and are indispensable supporting conditions for the life sciences and biomedicine industries. Specific pathogen-free (SPF) chicken embryos are used in the manufacture and quality control of biological product [4]; ducks play an important role in the research of avian 
TABLE 5: Number of alleles, effective alleles, effective heterozygosity, PIC, and Shannon's index of the outbred colony chicken samples.

\begin{tabular}{|c|c|c|c|c|c|}
\hline Loci & Observed number of alleles & Effective number of alleles & Shannon's information index & Effective heterozygosity & PIC \\
\hline MCW0029 & 4 & 2.931 & 1.209 & 0.579 & 0.603 \\
\hline GGNCAMZO & 2 & 1.069 & 0.146 & 0.060 & 0.062 \\
\hline ADL0293 & 5 & 3.200 & 1.311 & 0.573 & 0.634 \\
\hline ADL0317 & 7 & 5.236 & 1.768 & 0.554 & 0.783 \\
\hline GGAVIR & 3 & 1.916 & 0.796 & 0.456 & 0.408 \\
\hline ADL0201 & 5 & 2.103 & 1.013 & 0.429 & 0.482 \\
\hline GCT0016 & 5 & 3.042 & 1.274 & 0.337 & 0.618 \\
\hline ADL0304 & 6 & 4.641 & 1.627 & 0.666 & 0.751 \\
\hline MCW0402 & 8 & 6.042 & 1.881 & 0.702 & 0.813 \\
\hline MCW0063 & 7 & 4.319 & 1.626 & 0.568 & 0.736 \\
\hline ADL185 & 5 & 3.204 & 1.359 & 0.614 & 0.647 \\
\hline GGMYC & 2 & 1.800 & 0.637 & 0.427 & 0.346 \\
\hline LEI0094 & 6 & 3.674 & 1.468 & 0.562 & 0.683 \\
\hline LEI0074 & 4 & 3.707 & 1.348 & 0.597 & 0.681 \\
\hline ADL328 & 3 & 2.785 & 1.058 & 0.526 & 0.565 \\
\hline GGVITC & 1 & 1.000 & 0.000 & 0.000 & 1.000 \\
\hline GGANTECL & 3 & 2.897 & 1.080 & 0.600 & 0.580 \\
\hline LEI094 & 6 & 4.444 & 1.579 & 0.690 & 0.738 \\
\hline MCW0330 & 4 & 3.232 & 1.269 & 0.577 & 0.637 \\
\hline LEI0141 & 4 & 3.162 & 1.229 & 0.341 & 0.623 \\
\hline ADL0292 & 3 & 2.793 & 1.061 & 0.475 & 0.568 \\
\hline GGVITIIG & 2 & 1.965 & 0.684 & 0.460 & 0.371 \\
\hline MCW0087 & 8 & 5.930 & 1.898 & 0.544 & 0.810 \\
\hline MCW0347 & 3 & 1.948 & 0.815 & 0.447 & 0.419 \\
\hline ADL176 & 9 & 4.846 & 1.858 & 0.522 & 0.773 \\
\hline ADL166 & 5 & 3.729 & 1.380 & 0.574 & 0.682 \\
\hline MCW0014 & 5 & 4.342 & 1.543 & 0.592 & 0.735 \\
\hline GGCYMA & 3 & 1.603 & 0.632 & 0.317 & 0.322 \\
\hline Mean & 4.571 & 3.270 & 1.198 & 0.492 & 0.610 \\
\hline
\end{tabular}

TABLE 6: Number of alleles, effective alleles, effective heterozygosity, and Shannon's index of the haplotype chicken samples.

\begin{tabular}{lcccc}
\hline Loci & Observed number of alleles & Effective number of alleles & Shannon's information index & Effective heterozygosity \\
\hline GGNCAMZO & 1 & 1.000 & 0.000 & 0.673 \\
GGAVIR & 2 & 1.923 & 0.000 & 0.480 \\
MCW0402 & 1 & 1.000 & 0.000 & 0.000 \\
MCW0063 & 1 & 1.000 & 0.898 & 0.000 \\
ADL185 & 3 & 2.174 & 0.000 & 0.540 \\
GGMYC & 1 & 1.000 & 1.055 & 0.000 \\
LEI0094 & 3 & 2.778 & 0.000 & 0.640 \\
GGVITC & 1 & 1.000 & 0.500 & 0.000 \\
ADL0292 & 2 & 1.471 & 0.693 & 0.320 \\
GGVITIIG & 2 & 2.000 & 0.000 & 0.500 \\
ADL166 & 1 & 1.000 & 0.000 & 0.000 \\
MCW0014 & 1 & 1.000 & 0.000 & 0.000 \\
GGCYMA & 1 & 1.000 & 0.611 & 0.000 \\
STMSGGHU2-1A & 2 & 1.724 & 0.316 & 0.420 \\
Mean & 1.571 & 1.434 & & 0.207 \\
\hline
\end{tabular}


TABLE 7: Number of alleles, effective alleles, effective heterozygosity, PIC, and Shannon's index of outbred colony duck samples.

\begin{tabular}{|c|c|c|c|c|c|}
\hline Loci & Observed number of alleles & Effective number of alleles & Shannon's information index & Effective heterozygosity & PIC \\
\hline $\mathrm{CMO} 211$ & 8 & 4.628 & 1.698 & 0.764 & 0.752 \\
\hline CAUD011 & 9 & 5.024 & 1.835 & 0.799 & 0.775 \\
\hline CAUD027 & 9 & 3.698 & 1.588 & 0.654 & 0.696 \\
\hline APH09 & 8 & 4.840 & 1.728 & 0.756 & 0.763 \\
\hline AY314 & 12 & 7.285 & 2.165 & 0.806 & 0.848 \\
\hline AY258 & 9 & 3.503 & 1.586 & 0.700 & 0.684 \\
\hline CAUD018 & 4 & 2.941 & 1.194 & 0.640 & 0.596 \\
\hline CAUD031 & 8 & 4.459 & 1.711 & 0.730 & 0.746 \\
\hline CAUD026 & 7 & 4.674 & 1.697 & 0.750 & 0.757 \\
\hline CAUD023 & 7 & 2.725 & 1.315 & 0.584 & 0.591 \\
\hline CMO212 & 8 & 4.154 & 1.642 & 0.739 & 0.724 \\
\hline CAUD006 & 4 & 3.333 & 1.280 & 0.440 & 0.645 \\
\hline CAUD004 & 7 & 5.556 & 1.834 & 0.720 & 0.798 \\
\hline CAUD001 & 6 & 5.000 & 1.696 & 0.600 & 0.772 \\
\hline CAUD034 & 10 & 3.943 & 1.742 & 0.730 & 0.723 \\
\hline CAUD007 & 8 & 3.894 & 1.639 & 0.714 & 0.713 \\
\hline APL579 & 7 & 3.068 & 1.412 & 0.635 & 0.636 \\
\hline CAUD010 & 6 & 4.655 & 1.630 & 0.768 & 0.753 \\
\hline CAUD028 & 5 & 3.549 & 1.378 & 0.541 & 0.668 \\
\hline CAUD012 & 7 & 3.122 & 1.354 & 0.652 & 0.630 \\
\hline CAUD035 & 10 & 5.768 & 1.922 & 0.759 & 0.804 \\
\hline CAUD014 & 9 & 3.600 & 1.448 & 0.696 & 0.672 \\
\hline CAUD032 & 14 & 6.159 & 2.120 & 0.797 & 0.821 \\
\hline APH11 & 2 & 1.923 & 0.673 & 0.479 & 0.365 \\
\hline APL2 & 4 & 2.556 & 1.067 & 0.609 & 0.529 \\
\hline Mean & 7.520 & 4.162 & 1.574 & 0.683 & 0.698 \\
\hline
\end{tabular}

TABLE 8: Number of alleles, effective alleles, effective heterozygosity, and Shannon's index of haplotype duck samples.

\begin{tabular}{lcccc}
\hline Loci & $\begin{array}{c}\text { Observed } \\
\text { number of } \\
\text { alleles }\end{array}$ & $\begin{array}{c}\text { Effective } \\
\text { number of } \\
\text { alleles }\end{array}$ & $\begin{array}{c}\text { Shannon's } \\
\text { information } \\
\text { index }\end{array}$ & $\begin{array}{c}\text { Effective } \\
\text { heterozygosity }\end{array}$ \\
\hline CAUD002 & 3 & 2.020 & 0.857 & 0.360 \\
CAUD006 & 4 & 2.740 & 1.142 & 0.540 \\
CAUD018 & 3 & 1.802 & 0.746 & 0.400 \\
CAUD005 & 5 & 3.945 & 1.490 & 0.551 \\
APL579 & 5 & 2.632 & 1.205 & 0.500 \\
APH18 & 7 & 4.301 & 1.655 & 0.640 \\
CAUD010 & 3 & 2.597 & 1.010 & 0.420 \\
CAUD028 & 2 & 1.980 & 0.688 & 0.360 \\
CAUD012 & 3 & 2.597 & 1.010 & 0.420 \\
CAUD035 & 4 & 3.756 & 1.353 & 0.605 \\
CAUD014 & 4 & 3.509 & 1.306 & 0.580 \\
CAUD026 & 4 & 2.740 & 1.142 & 0.520 \\
CMO212 & 5 & 3.774 & 1.458 & 0.640 \\
AY258 & 4 & 2.353 & 1.063 & 0.500 \\
CAUD034 & 6 & 2.198 & 1.164 & 0.460 \\
Mean & 4.133 & 2.863 & 1.153 & 0.500 \\
\hline
\end{tabular}

influenza, fatty liver, duck hepatitis A, and duck hepatitis B [5-7]; goose blood contains a higher concentration of immunoglobulin, which is often used in pharmacology and toxicology research [8]; pigeons belong to the class of birds and are considered as important animal model in avian influenza research [9]. With the increasing demand for experiment poultry, people are paying more attention to the genetic structure analysis and genetic quality control. However, the current methods of genetic structure analysis and genetic quality control for experimental poultry animals are insufficient.

Coat colour gene testing method, biochemical marker gene testing method, immune marker gene testing method, and DNA molecular marker method are popular methods for genetic monitoring. Microsatellite DNA, mitochondrial DNA (mtDNA), restriction fragment length polymorphism (PCR-RFLP), single-stranded conformation polymorphism (PCR-SSCP), and specific gene polymorphisms are commonly used DNA molecular marker methods [24-27]. Among them, microsatellite DNA has become valuable tools for evaluating population genetic diversity due to their unique virtue.

Microsatellite DNA is characterized by short tandem repeats (STRs) of 1 to 6 nucleotides in eukaryotic genome with a random manner [28]. It has rich polymorphism and 
TABLE 9: Number of alleles, effective alleles, effective heterozygosity, PIC, and Shannon's index of outbred colony goose samples.

\begin{tabular}{|c|c|c|c|c|c|}
\hline Loci & Observed number of alleles & Effective number of alleles & Shannon's information index & Effective heterozygosity & PIC \\
\hline G-Ans17 & 4 & 1.843 & 0.775 & 0.441 & 0.388 \\
\hline G-TTUCG1 & 3 & 2.255 & 0.943 & 0.381 & 0.494 \\
\hline G-APH13 & 4 & 1.605 & 0.752 & 0.315 & 0.352 \\
\hline G-Ans02 & 8 & 5.389 & 1.837 & 0.749 & 0.790 \\
\hline G-Ans07 & 4 & 3.073 & 1.220 & 0.634 & 0.613 \\
\hline G-Ans18 & 3 & 2.208 & 0.922 & 0.309 & 0.481 \\
\hline G-Ans 25 & 4 & 3.333 & 1.282 & 0.629 & 0.647 \\
\hline G-Hhi $\mu 1 \mathrm{~b}$ & 4 & 2.965 & 1.147 & 0.471 & 0.594 \\
\hline G-CKW47 & 4 & 3.143 & 1.238 & 0.573 & 0.623 \\
\hline G-Bса $\mu 5$ & 3 & 2.728 & 1.051 & 0.469 & 0.562 \\
\hline G-Bса $\mu 7$ & 6 & 2.731 & 1.158 & 0.455 & 0.562 \\
\hline G-Bса $\mu 8$ & 7 & 2.845 & 1.290 & 0.635 & 0.599 \\
\hline G-CAUD006 & 4 & 3.704 & 1.344 & 0.602 & 0.680 \\
\hline G-APH20 & 8 & 4.713 & 1.772 & 0.734 & 0.761 \\
\hline Mean & 4.714 & 3.038 & 1.195 & 0.528 & 0.582 \\
\hline
\end{tabular}

Table 10: Number of alleles, effective alleles, effective heterozygosity, PIC, and Shannon's index of outbred colony pigeon samples.

\begin{tabular}{|c|c|c|c|c|c|}
\hline Loci & Observed number of alleles & Effective number of alleles & Shannon's information index & Effective heterozygosity & PIC \\
\hline UU-Cli02 & 5 & 3.613 & 1.374 & 0.694 & 0.672 \\
\hline UU-Cli06 & 4 & 2.921 & 1.163 & 0.383 & 0.593 \\
\hline PG5 & 2 & 1.681 & 0.595 & 0.397 & 0.323 \\
\hline C26L9(1265223) & 4 & 2.576 & 1.076 & 0.602 & 0.533 \\
\hline UU-Cli14 & 10 & 5.144 & 1.923 & 0.787 & 0.784 \\
\hline C12L1(532572) & 4 & 2.810 & 1.118 & 0.487 & 0.575 \\
\hline C12L4(906353) & 11 & 6.375 & 2.052 & 0.766 & 0.825 \\
\hline Cli $\mu \mathrm{D} 11$ & 7 & 4.541 & 1.682 & 0.734 & 0.750 \\
\hline C26L10(1404758) & 11 & 9.118 & 2.281 & 0.860 & 0.880 \\
\hline C26L4(568923) & 13 & 5.854 & 2.062 & 0.807 & 0.812 \\
\hline PG4 & 10 & 6.847 & 2.017 & 0.767 & 0.836 \\
\hline UU-Cli12 & 8 & 2.825 & 1.364 & 0.623 & 0.599 \\
\hline Cli $\mu \mathrm{T} 47$ & 7 & 3.492 & 1.413 & 0.658 & 0.666 \\
\hline Cli $\mu \mathrm{D} 32$ & 9 & 6.695 & 1.991 & 0.807 & 0.833 \\
\hline UU-Cli07 & 5 & 1.352 & 0.592 & 0.252 & 0.251 \\
\hline C26L1(20390) & 16 & 7.014 & 2.244 & 0.759 & 0.844 \\
\hline Mean & 7.875 & 4.554 & 1.559 & 0.649 & 0.674 \\
\hline
\end{tabular}

TABLE 11: Comparison of mean observed allele number, mean effective allele number, mean Shannon's index, and mean effective heterozygosity among the outbred colonies of chickens.

\begin{tabular}{lcccc}
\hline Colonies & $\begin{array}{c}\text { Mean observed number } \\
\text { of alleles }\end{array}$ & $\begin{array}{c}\text { Mean effective number } \\
\text { of alleles }\end{array}$ & $\begin{array}{c}\text { Mean Shannon's } \\
\text { information index }\end{array}$ & $\begin{array}{c}\text { Mean effective } \\
\text { heterozygosity }\end{array}$ \\
\hline BWEL & 2.857 & 2.024 & 0.730 & 0.424 \\
BM & 2.857 & 2.132 & 0.802 & 0.485 \\
Beijing oil chicken & 4.464 & 2.821 & 1.088 & 0.569 \\
\hline
\end{tabular}


TABLE 12: Comparison of mean observed allele number, mean effective allele number, mean Shannon's index, and mean effective heterozygosity among the haplotype chickens.

\begin{tabular}{lcccc}
\hline Colonies & $\begin{array}{c}\text { Mean } \\
\text { observed } \\
\text { number of } \\
\text { alleles }\end{array}$ & $\begin{array}{c}\text { Mean } \\
\text { effective } \\
\text { number of } \\
\text { alleles }\end{array}$ & $\begin{array}{c}\text { Mean } \\
\text { Shannon's } \\
\text { information } \\
\text { index }\end{array}$ & $\begin{array}{c}\text { Mean effective } \\
\text { heterozygosity }\end{array}$ \\
\hline G1 & 1.571 & 1.434 & 0.316 & 0.207 \\
G2 & 1.643 & 1.409 & 0.335 & 0.224 \\
G7 & 2.000 & 1.626 & 0.548 & 0.364 \\
\hline
\end{tabular}

TABLE 13: Comparison of mean observed allele number, mean effective allele number, mean Shannon's index, and mean effective heterozygosity among the outbred colonies of ducks.

\begin{tabular}{lcccc}
\hline Colonies & $\begin{array}{c}\text { Mean } \\
\text { observed } \\
\text { number of } \\
\text { alleles }\end{array}$ & $\begin{array}{c}\text { Mean } \\
\text { effective } \\
\text { number of } \\
\text { alleles }\end{array}$ & $\begin{array}{c}\text { Mean } \\
\text { Shannon's } \\
\text { information } \\
\text { index }\end{array}$ & $\begin{array}{c}\text { Mean effective } \\
\text { heterozygosity }\end{array}$ \\
\hline 1 & 6.320 & 3.518 & 1.410 & 0.685 \\
$\mathrm{JD}$ & 5.280 & 3.466 & 1.335 & 0.680 \\
\hline
\end{tabular}

TABle 14: Comparison of mean observed allele number, mean effective allele number, mean Shannon's index, and mean effective heterozygosity among the haplotype ducks.

\begin{tabular}{lcccc}
\hline Colonies & $\begin{array}{c}\text { Mean } \\
\text { observed } \\
\text { number of } \\
\text { alleles }\end{array}$ & $\begin{array}{c}\text { Mean } \\
\text { effective } \\
\text { number of } \\
\text { alleles }\end{array}$ & $\begin{array}{c}\text { Mean } \\
\text { Shannon's } \\
\text { information } \\
\text { index }\end{array}$ & $\begin{array}{c}\text { Mean effective } \\
\text { heterozygosity }\end{array}$ \\
\hline A & 2.400 & 2.022 & 0.760 & 0.489 \\
B & 2.333 & 2.029 & 0.745 & 0.484 \\
C & 2.400 & 1.912 & 0.726 & 0.459 \\
D & 2.333 & 1.944 & 0.701 & 0.442 \\
\hline
\end{tabular}

large genetic information. Microsatellite can be used to distinguish heterozygous from homozygous because of their codominant inheritance feature [29]. In previous studies, microsatellites have been used as biomarkers for monitoring rodent genetic traits [30,31]. With the deep understanding of microsatellites, it plays a more important role in genetic monitoring for being simple, clear, and stable in operation. In this research, we screened out microsatellite loci with suitable length and high specificity as candidate loci by gel electrophoresis firstly. Then, we performed STR scanning on these candidate loci. Microsatellite loci with good polymorphism, abundant alleles in the outbred groups, and good monomorphism in the haplotype populations were selected to form the microsatellite marker system. We analyzed the average effective allele number, average Shannon's index, average effective heterozygosity, and other analytical indices to estimate genetic variation in different groups.

The mean effective number of alleles is an indicator of genetic variation and mutation drift balance. In our study, Beijing oil chicken has the highest mean effective allele number of three outbred chicken populations; outbred duck group 1 has higher mean effective allele number than outbred duck group JD. The outbred goose group Guangdong Wuzong and outbred pigeon group white king have the highest mean number of effective alleles in outbred goose populations and outbred pigeon populations, respectively. The higher mean effective number of alleles indicates that the population can maintain the original gene and avoid new variations under the pressures from genetic drift and artificial selection. The results show that Beijing oil chicken, outbred duck group 1, Guangdong Wuzong goose, and white king pigeon are the most stable strains in the outbred group of experiment chicken, duck, goose, and pigeon groups in this research, respectively.

The mean effective heterozygosity of a population is an important indicator of population genetic diversity and can reflect the richness of the detected genes. It is generally believed that when the mean effective heterozygosity of the population is less than 0.5 , it indicates that the individual differences in the population are small and the genetic heterozygosity is low, which does not conform to the genetic characteristics of an outbred group animal. When the mean effective heterozygosity of the population is higher than 0.7 , its genetic diversity is high [32].

Hence, we found that the mean effective heterozygosity of BWEL, BM, and Beijing oil chicken groups is all greater than 0.5 , which conforms to the characteristics of the outbred group. The mean effective heterozygosity of BWEL and BM chicken groups is nearly 0.5 . The average effective heterozygosity of G1, G2, and G7 groups is all less than 0.5. It is also consistent with the background that BWEL, BM, and Beijing oil chickens are outbred colonies; Beijing oil chicken has abundant genetic diversity and high selection potential for it has the highest mean effective heterozygosity among the outbred chicken groups in this study. This may be due to the large population. Duck group 1 and JD duck all have a mean effective heterozygosity greater than 0.680 which indicates a high genetic diversity. The mean effective heterozygosity of Guangdong Wuzong goose group, silver king pigeon group, and white king pigeon group is all greater than 0.5 which reflects abundant genetic diversity. The mean effective heterozygosity of three haplotype chicken groups and four haplotype duck groups is 0.207 and 0.500 , respectively. The result indicates a good consistency in haplotype chickens and ducks. This may be the result of long-term full-sib and half-sib reproduction. Chickens and ducks are more widely used in biological research, and the breeding standards are stricter, while geese and pigeons are more useful in agriculture. Haplotype chickens have lower mean effective heterozygosity than haplotype duck populations, which is consistent with a longer history of breeding in experimental chickens.

When measuring the degree of gene variation, PIC is often used as a variation index. It is generally believed that when PIC is between 0.25 and 0.5 , it is moderately polymorphic, and $<0.25$ shows a low level of polymorphism, when PIC is greater than 0.5 , it means a high level of polymorphism [33]. In our microsatellite marker system, most of the microsatellite sites have a PIC greater than 0.5 that show high 
TABle 15: Comparison of mean observed allele number, mean effective allele number, mean Shannon's index, and mean effective heterozygosity among the outbred colonies of geese.

\begin{tabular}{lcccc}
\hline Colonies & $\begin{array}{c}\text { Mean observed number } \\
\text { of alleles }\end{array}$ & $\begin{array}{c}\text { Mean effective number } \\
\text { of alleles }\end{array}$ & $\begin{array}{c}\text { Mean Shannon's } \\
\text { information index }\end{array}$ & $\begin{array}{c}\text { Mean effective } \\
\text { heterozygosity }\end{array}$ \\
\hline Guangdong Wuzong & 4.000 & 2.769 & 1.112 & 0.618 \\
Yangzhou & 3.714 & 2.155 & 0.802 & 0.439 \\
\hline
\end{tabular}

TABle 16: Comparison of mean observed allele number, mean effective allele number, mean Shannon's index, and mean effective heterozygosity among the outbred colonies of pigeons.

\begin{tabular}{lcccc}
\hline Colonies & $\begin{array}{c}\text { Mean } \\
\text { observed } \\
\text { number of } \\
\text { alleles }\end{array}$ & $\begin{array}{c}\text { Mean } \\
\text { effective } \\
\text { number of } \\
\text { alleles }\end{array}$ & $\begin{array}{c}\text { Mean } \\
\text { Shannon's } \\
\text { information } \\
\text { index }\end{array}$ & $\begin{array}{c}\text { Mean effective } \\
\text { heterozygosity }\end{array}$ \\
\hline $\begin{array}{l}\text { Silver } \\
\text { king }\end{array}$ & 6.125 & 3.260 & 1.307 & 0.647 \\
$\begin{array}{l}\text { White } \\
\text { king }\end{array}$ & 7.375 & 4.247 & 1.435 & 0.651 \\
\hline
\end{tabular}

polymorphism. All these data prove that our microsatellite marker system provides rich genetic information, which can be used as effective genetic markers. In our study, highly polymorphic microsatellite marker systems showed powerful markers for quantifying genetic variations within and between poultry populations. We will collect more samples to make a more accurate description of genetic structure of the Chinese experimental chickens, ducks, geese, and pigeons in the future [34].

\section{Conclusions}

In conclusion, we identified appropriate microsatellite marker systems for native experimental chickens, ducks, geese, and pigeons in China. The combination of loci selected in our research provides a good choice for genetic monitoring of the quality and the population genetic diversity of poultry stocks.

\section{Data Availability}

All data, models, and code generated or used during the study appear in the submitted article.

\section{Conflicts of Interest}

The authors declare that there is no conflict of interest regarding the publication of this paper.

\section{Acknowledgments}

We are very grateful to the Institute of Animal Science, Chinese Academy of Agricultural Sciences, Harbin Veterinary Research Institute, Southern Medical University and Yangzhou University for providing animal samples for this study. This work was supported by the Beijing Municipal Science and Technology Projects (No. D181100000518002), Support Project of High-level Teachers in Beijing Municipal Universi- ties in the Period of 13th Five-year Plan (Grant Number IDHT20170516), and the National Key Research and Development Plan of China (No. 2017YFD0501602).

\section{Supplementary Materials}

Supplementary Table 1: number of alleles, effective alleles, effective heterozygosity, and Shannon's index of the G1 haplotype chicken population. Supplementary Table 2: number of alleles, effective alleles, effective heterozygosity, and Shannon's index of the G2 haplotype chicken population. Supplementary Table 3: number of alleles, effective alleles, effective heterozygosity, and Shannon's index of the G7 haplotype chicken population. Supplementary Table 4: number of alleles, effective alleles, effective heterozygosity, and Shannon's index of the A haplotype duck population. Supplementary Table 5: number of alleles, effective alleles, effective heterozygosity, and Shannon's index of the B haplotype duck population. Supplementary Table 6: number of alleles, effective alleles, effective heterozygosity, and Shannon's index of the C haplotype duck population. Supplementary Table 7: number of alleles, effective alleles, effective heterozygosity, and Shannon's index of the D haplotype duck population. (Supplementary Materials)

\section{References}

[1] E. P. Neff, "What is a lab animal?," Lab Anim (NY), vol. 47, no. 9, pp. 223-227, 2018.

[2] M. B. Bello, K. Yusoff, A. Ideris, M. Hair-Bejo, B. P. H. Peeters, and A. R. Omar, "Diagnostic and vaccination approaches for Newcastle disease virus in poultry: the current and emerging perspectives," BioMed Research International, vol. 2018, 18 pages, 2018.

[3] M. L. Dequéant and O. Pourquié, "Chicken genome: new tools and concepts," Developmental dynamics : an official publication of the American Association of Anatomists, vol. 232, no. 4, pp. 883-886, 2005.

[4] H. B. Yin, C. H. Chen, M. J. Darre, A. M. Donoghue, D. J. Donoghue, and K. Venkitanarayanan, "Phytochemicals reduce aflatoxin-induced toxicity in chicken embryos," Poultry Science, vol. 96, no. 10, pp. 3725-3732, 2017.

[5] A. M. Ramey, A. B. Reeves, J. Z. Drexler et al., "Influenza A viruses remain infectious for more than seven months in northern wetlands of North America," Proceedings of the Royal Society B: Biological Sciences, vol. 287, no. 1934, p. 20201680, 2020.

[6] Y. Fu, M. Pan, X. Wang, Y. Xu, H. Yang, and D. Zhang, "Molecular detection and typing of duck hepatitis A virus directly from clinical specimens," Veterinary Microbiology, vol. 131, no. 3-4, pp. 247-257, 2008. 
[7] Q. Pan, L. Liu, Y. Wang et al., "The first whole genome sequence and pathogenicity characterization of a fowl adenovirus 4 isolated from ducks associated with inclusion body hepatitis and hydropericardium syndrome," Avian Pathology, vol. 46, no. 5, pp. 571-578, 2017.

[8] T. Huang, K. Wu, X. Yuan et al., "Molecular analysis of the immunoglobulin genes in goose," Developmental and Comparative Immunology, vol. 60, pp. 160-166, 2016.

[9] J. H. Kwon, Y. K. Noh, D. H. Lee et al., "Experimental infection with highly pathogenic $\mathrm{H} 5 \mathrm{~N} 8$ avian influenza viruses in the mandarin duck (Aix galericulata) and domestic pigeon (Columba livia domestica)," Veterinary Microbiology, vol. 203, pp. 95-102, 2017.

[10] M. Nunome, K. Kinoshita, S. Ishishita, Y. Ohmori, A. Murai, and Y. Matsuda, "Genetic diversity of 21 experimental chicken lines with diverse origins and genetic backgrounds," Experimental Animals, vol. 68, no. 2, pp. 177-193, 2019.

[11] M. G. Strillacci, M. C. Cozzi, E. Gorla et al., "Genomic and genetic variability of six chicken populations using single nucleotide polymorphism and copy number variants as markers," Animal : an international journal of animal bioscience, vol. 11, no. 5, pp. 737-745, 2017.

[12] H. Khatib, E. Genislav, L. B. Crittenden, N. Bumstead, and M. Soller, "Sequence-tagged microsatellite sites as markers in chicken reference and resource populations," Animal Genetics, vol. 24, no. 5, pp. 355-362, 1993.

[13] C. Gao, L. Han, J. Han et al., "Establishment of six homozygous MHC-_B_haplotype populations associated with susceptibility to Marek 's disease in Chinese specific pathogen-free BWEL chickens," Infection, Genetics and Evolution, vol. 29, pp. 15-25, 2015.

[14] D. Seo, M. S. Bhuiyan, H. Sultana, J. M. Heo, and J. H. Lee, "Genetic diversity analysis of south and east Asian duck populations using highly polymorphic microsatellite markers," Asian-Australasian Journal of Animal Sciences, vol. 29, no. 4, pp. 471-478, 2016.

[15] S. A. Stringham, E. E. Mulroy, J. Xing et al., "Divergence, convergence, and the ancestry of feral populations in the domestic rock pigeon," Current biology : CB, vol. 22, no. 4, pp. 302-308, 2012.

[16] J. H. Seo, J. H. Lee, and H. S. Kong, "Assessment of genetic diversity and phylogenetic relationships of Korean native chicken breeds using microsatellite markers," Asian-Australasian Journal of Animal Sciences, vol. 30, no. 10, pp. 13651371, 2017.

[17] B. H. Rudresh, H. N. N. Murthy, M. R. Jayashankar, C. S. Nagaraj, A. M. Kotresh, and S. M. Byregowda, "Microsatellite based genetic diversity study in indigenous chicken ecotypes of Karnataka," Veterinary world, vol. 8, no. 8, pp. 970-976, 2015.

[18] Y. Huang, J. Tu, X. Cheng et al., "Characterization of 35 novel microsatellite DNA markers from the duck (Anas platyrhynchos) genome and cross-amplification in other birds," Genetics, selection, evolution : GSE, vol. 37, no. 5, pp. 455472, 2005.

[19] Y. Su, R. Long, G. Chen, X. Wu, K. Xie, and J. Wan, "Genetic analysis of six endangered local duck populations in China based on microsatellite markers," Journal of Genetics and Genomics, vol. 34, pp. 1010-1018, 2007.

[20] J. C.-I. Lee, L.-C. Tsai, Y.-Y. Kuan et al., "Racing pigeon identification using STR and chromo-helicase DNA binding gene markers," Electrophoresis, vol. 28, no. 23, pp. 4274-4281, 2007.
[21] K. Andres and E. Kapkowska, "Applicability of anatid and galliform microsatellite markers to the genetic diversity studies of domestic geese (Anser anser domesticus) through the genotyping of the endangered zatorska breed," BMC Research Notes, vol. 4, no. 1, pp. 1-10, 2011.

[22] R. Parada, J. Ksiazkiewicz, M. Kawka, and K. Jaszczak, “Studies on resources of genetic diversity in conservative flocks of geese using microsatellite DNA polymorphic markers," Molecular Biology Reports, vol. 39, no. 5, pp. 5291-5297, 2012.

[23] N. R. Lebas and P. B. Spencer, "Polymorphic microsatellite markers in the ornate dragon lizard, Ctenophorus ornatus," Molecular ecology, vol. 9, no. 3, pp. 365-366, 2000.

[24] I. Barbaric, M. Stewart, S. Wells, and T. N. Dear, "A new coat color mouse line for testing germline transmission of embryonic stem cells while retaining an inbred genetic background," Journal of the American Association for Laboratory Animal Science, vol. 46, no. 3, pp. 37-40, 2007.

[25] M. N. Weitzmann, K. J. Woodford, and K. Usdin, "The mouse Ms6-hm hypervariable microsatellite forms a hairpin and two unusual tetraplexes," The Journal of Biological Chemistry, vol. 273, no. 46, pp. 30742-30749, 1998.

[26] G. Bulfield and G. Bantin, "Genetic monitoring of inbred strains of mice using electrophoresis and electrofocusing," Laboratory Animals, vol. 15, no. 2, pp. 147-149, 1981.

[27] J. R. Fahey, H. Katoh, R. Malcolm, and A. V. Perez, “The case for genetic monitoring of mice and rats used in biomedical research," Mammalian genome : official journal of the International Mammalian Genome Society, vol. 24, no. 3-4, pp. 89-94, 2013.

[28] Y. C. Li, A. B. Korol, T. Fahima, A. Beiles, and E. Nevo, "Microsatellites: genomic distribution, putative functions and mutational mechanisms: a review," Molecular Ecology, vol. 11, no. 12, pp. 2453-2465, 2002.

[29] A. Grover and P. C. Sharma, "Development and use of molecular markers: past and present," Critical Reviews in Biotechnology, vol. 36, no. 2, pp. 290-302, 2014.

[30] X. Liu, X. Yu, Y. Xu et al., "Development of an effective microsatellite marker system to determine the genetic structure of Meriones meridianus populations," Experimental Animals, vol. 69, no. 2, pp. 224-232, 2020.

[31] X. Y. Du, W. Li, X. Y. Sa et al., "Selection of an effective microsatellite marker system for genetic control and analysis of gerbil populations in China," Genetics and Molecular Research, vol. 14, no. 3, pp. 11030-11042, 2015.

[32] R. Chakraborty, Y. Zhong, M. de Andrade, P. R. Clemens, R. G. Fenwick, and C. T. Caskey, "Linkage disequilibria among (CA)n polymorphisms in the human dystrophin gene and their implications in carrier detection and prenatal diagnosis in Duchenne and Becker muscular dystrophies," Genomics, vol. 21, no. 3, pp. 567-570, 1994.

[33] T. Vanhala, M. Tuiskula-Haavisto, K. Elo, J. Vilkki, and A. Mäki-Tanila, "Evaluation of genetic variability and genetic distances between eight chicken lines using microsatellite markers," Poultry Science, vol. 77, no. 6, pp. 783-790, 1998.

[34] J. K. Pritchard, M. Stephens, and P. Donnelly, "Inference of population structure using multilocus genotype data," Genetics, vol. 155, no. 2, pp. 945-959, 2000. 